\title{
On the limits of climate reconstruction from water stable isotopes in polar ice cores
}

Mathieu Casado, A. J. Orsi and A. Landais

\begin{abstract}
Ice core water stable isotopes are a favored proxy to reconstruct past climatic variations. Yet, their interpretation requires calibration from other proxy records and is affected by various processes which alter the signal after it has been imprinted.
\end{abstract}

The isotopic composition $\left(\delta^{18} \mathrm{O}, \delta^{17} \mathrm{O}\right.$ and $\delta D)$ of snow is linked to the condensation temperature because of fractionation associated with distillation from the evaporation site to the precipitation site (Dansgaard 1953). Over large ice sheets, ice is preserved for thousands of years (EPICA 2004) and, thus, analyzing the isotopic composition of the successive layers provides continuous, high-resolution indicators of past climatic variations.

A classical way to retrieve temperature from isotopic composition is to use the spatial relationship between $\delta^{18} \mathrm{O}$ of surface snow and surface temperature (e.g. Lorius and Merlivat 1975, for Antarctica). However, one should keep in mind two main limitations when using such a method. First, it assumes that the spatial relationship between $\delta^{18} \mathrm{O}$ and temperature is a good surrogate for the temporal relationship between $\delta^{18} \mathrm{O}$ and temperature although this link is known to change with time. Second, post-deposition processes affect the snow stratigraphy and the isotopic composition of the snow after precipitation. In the end, the produced time series are also modulated by variable depth-to-time transfer function due to accumulation variations, ice thinning and diffusion.

\section{Resolution and noise}

The local accumulation is a determining factor for both the extent of an ice-core record and the maximal resolution that can be achieved. As the ice thickness is capped between 3 and $4 \mathrm{~km}$, depending mainly on the geothermal flux and the topography, it is necessary to choose a site with low accumulation to obtain an ice record spanning several glacial-interglacial cycles (Fischer et al. 2013)

For sites with low accumulation, the snow is exposed at the surface for a long time. Hence, the initial precipitation signal is modified by local post-deposition processes (Ekaykin et al. 2002) due to snow-air interactions, such as the impact of metamorphism, wind and surface roughness, and diffusion. It prevents proper recording of the signal at the intra-seasonal and seasonal scale for sites with accumulation lower than $8 \mathrm{~cm}$ ice equivalent per year (Münch et al. 2016).

Deeper in the firn, diffusion smooths the isotopic composition time series, erasing part of the climatic signal (Johnsen 1977). This limits the interpretation of ice-core records at timescales smaller than a few decades.

Finally, for longer timescales (and thus deeper in the ice), the varying depth-toage transfer function affects the spectral properties of the isotopic composition. The first limitation is the accumulation rate itself, which decreases during glacial periods as a thermodynamic response to temperature decrease. The temporal resolution also gets lower with depth due to ice thinning. As illustrated in Figure 1, the number of years per meter globally increases with the depth of the record, from roughly 20 years per meter at the top of the core at Dome C, up to 1400 years per meter for glacial periods at the bottom. Overall, the variability found in single icecore records combines both the climate variability and several signatures of the archiving process itself.

\section{Isotope to temperature calibration} The calibration of $\delta^{18} \mathrm{O}$ to temperature can be tested against independent temperature time series, such as borehole measurements at the ice-core site. These
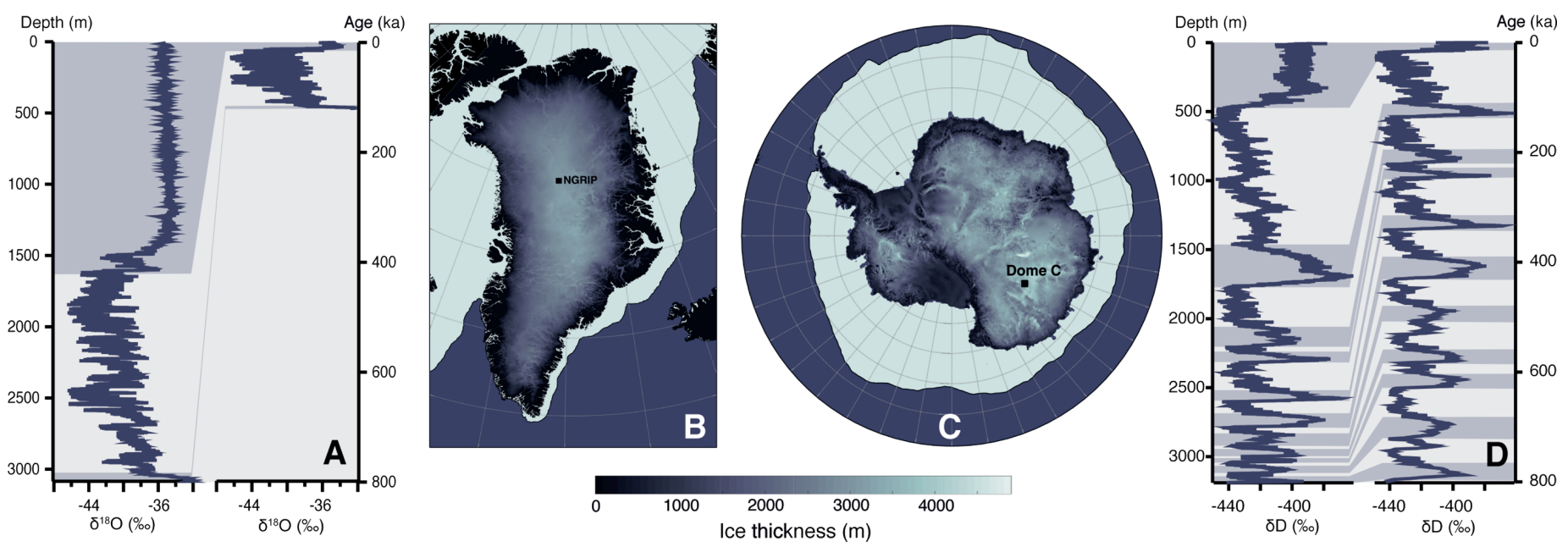

Figure 1: Greenland and Antarctic ice-core sites. (A) Isotopic signal from the NGRIP ice core. (B) and (C) maps of ice thickness in Greenland and Antarctica, respectively. (D) isotopic signal from the Dome $\mathrm{C}$ ice core. 


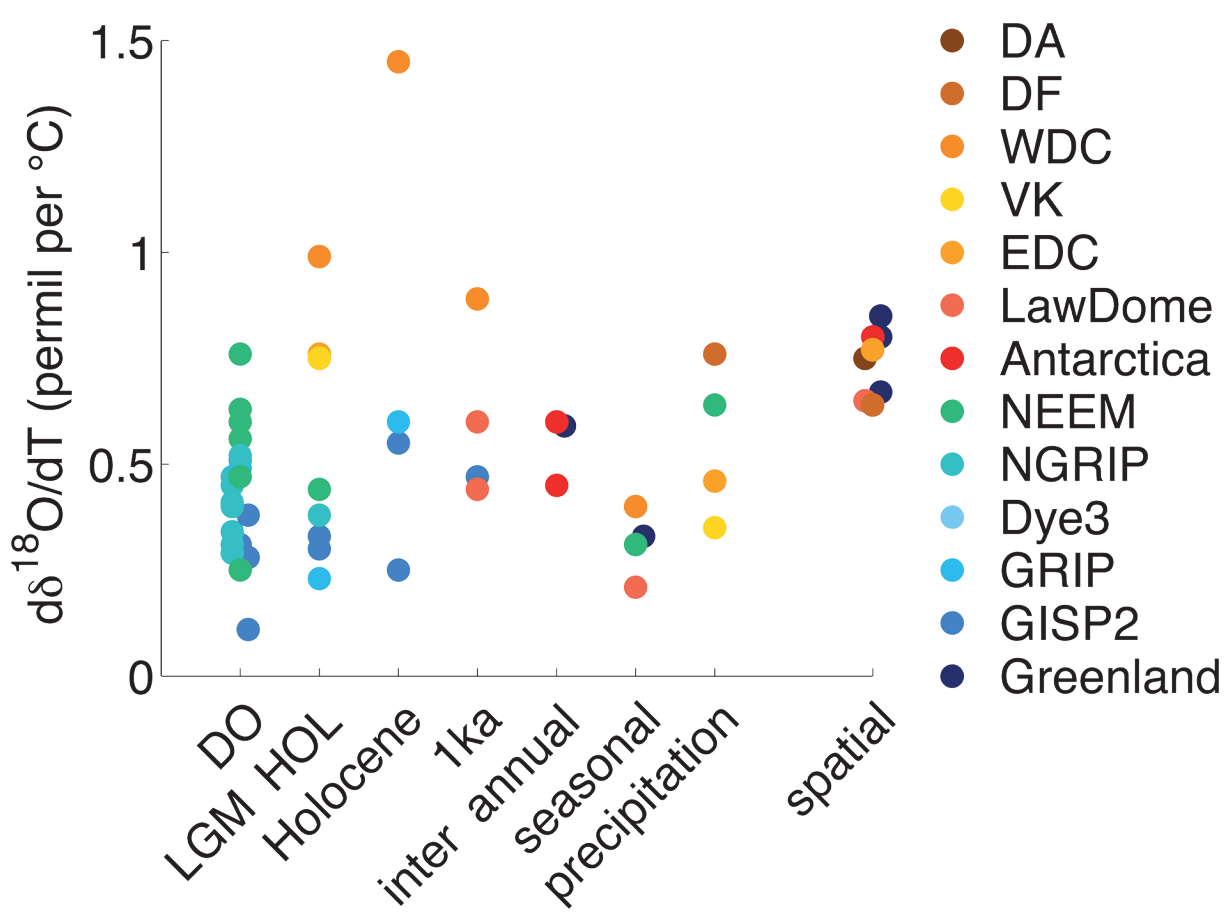

Figure 2: Slopes between isotopes and temperature for different locations and timescales.

measurements performed in Greenland have suggested that the use of the spatial slope (measurements made through space) to estimate the amplitude of the temperature change between the last glacial maximum (LGM) and present-day underestimates by a factor of two the true amplitude of the temperature change (Cuffey et al. 1994). Jouzel et al. (2003) also showed using simulations that the temporal slope (measurements made through time) linking isotopic composition to temperature is less steep than the spatial one and that it does not remain constant over time. This large variability can be due to differences in the large-scale atmospheric circulation, vertical structure of the atmosphere, the seasonality of precipitation, modification of location, or climatic conditions in the moisture source regions.

To take into account the changes in processes involved in the formation of the isotopic signal, calibration of the isotopic paleothermometer is realized through different methods. Weather station data are used at the seasonal and interannual scale, borehole temperature measurements are used at the scale of the recent anthropogenic warming (Orsi et al. 2017) or for the LGM-Holocene transition, and isotopes of nitrogen and argon can be used during abrupt warming events in Greenland (Guillevic et al. 2013). Isotope-enabled climate models can also be used to infer the isotope-temperature relationship with a direct control on the timescale and on the period: for instance, Sime et al. (2009) highlighted that for warm interglacial conditions, the isotope-temperature relationship can become non linear whereas it is not the case for cooler (glacial) conditions.

The ensemble of slopes $\delta^{18} \mathrm{O}$ versus temperature found in the literature (Fig. 2) shows, at all timescales, a large span of values ranging from 0.2 to $1.5 \% \circ{ }^{\circ} \mathrm{C}^{-1}$ which differs from the mostly constant spatial slopes. From this compilation, it is clear that neither the seasonal temporal slope nor the spatial slope, which are the most direct to measure, can be used to calibrate the relationship for longer time periods. For instance, work on DansgaardOeschger events (abrupt warming events during glacial periods typically spanning from decadal to centennial scales) showed that, even for events of a similar timescale, at the same site, the scaling is not preserved (Guillevic et al. 2013). This shows that a more complex framework than simple linear regression to temperature is necessary to interpret the isotopic signal.

These variations in the temperature sensitivity need to be properly taken into account before stacking cores from different sites, or computing power spectra, as the respective amplitude of different spectral peaks of $\delta^{18} \mathrm{O}$ variability may include more than one driver (climatic or not).

\section{Conclusions}

If water isotopes from ice-core records are insightful tools to reconstruct past climates, there are fundamental limits to their power of reconstruction.

First, the resolution of the ice-core record is not constant in time, due to changes in the accumulation rate, thinning due to ice flow, post-deposition processes, and diffusion of the water isotope signal in snow and ice. Spectral properties of icecore water isotopes time series are thus affected. For instance, for low accumulation sites, such as those found on the East Antarctic Plateau (below eight $\mathrm{cm}$ per year, ice equivalent), multi-decadal resolution at best can be extracted for the isotopic signal, even for recent periods, whereas in Greenland, where larger accumulation is found, seasonal cycles can be retrieved for the last 1,000 years from ice-core records.
Second, the relationship between isotopes and temperature is not constant in time and space. As a result, different methods should be applied to calibrate the isotopic paleothermometer: e.g. borehole temperature for glacial-interglacial transition (millennial scale) or $\delta^{15} \mathrm{~N}$ for rapid climatic variations (decadal to centennial scales).

These observations call for a more careful use of isotopic records when these timeseries are used for general inferences about the climate system (e.g. Huybers and Curry 2006), keeping in mind the variety of processes involved in the archiving of the climatic signal in the snow isotopic composition. Several approaches can help to clearly identify the transfer function leading to the isotopic signal from ice-core records: isotope-enabled global climate models are the way forward to refine the relationship between precipitation $\delta^{18} \mathrm{O}$ and temperature (Sime et al. 2009), and field studies (Casado et al. 2016) can help evaluate how this signal is modified after the deposition and how the isotope-totemperature relationship is altered at the seasonal and interannual timescales. Finally, using proxy system models can help quantify the impact of archival processes on the climate signal (Evans et al. 2013).

\section{AFFILIATIONS}

Laboratoire des Sciences du Climat et de I'Environnement, Université Paris-Saclay, Gif-surYvette, France

\section{CONTACT}

Mathieu Casado: mathieu.casado@gmail.com

\section{REFERENCES}

Casado M et al. (2016) Atmos Chem Phys 16: 8521-8538 Cuffey KM et al. (1994) J. Glaciol 40: 341-349

\section{Dansgaard W (1953) Tellus 5: 461-469}

Ekaykin AA et al. (2002) Ann Glaciol 35: 181-186

\section{EPICA (2004) Nature 429: 623-628}

Evans MN et al. (2013) Quat Sci Rev 76: 16-28 Fischer H et al. (2013) Clim Past 9: 2489-2505 Guillevic M et al. (2013) Clim Past 9: 1029-1051 Huybers P, Curry W (2006) Nature 441: 329-332

Johnsen S (1977) Proc Symp on Isotopes and impurities in snow and ice, Grenoble 1975, 118: 210-219

Jouzel J et al. (2003) J Geophys Res Atmos 108(D12): 4361

Lorius C, Merlivat L (1975) General assembly of the International Union of Geodesy and Geophysics, Grenoble 1975, 18pp

Münch T et al. (2016) Clim Past 12: 1565-1581

Orsi AJ et al. (2017) Geophys Res Lett 44: 6235-6243

Sime LC et al. (2009) Nature 462: 342-345 